\title{
Haematological, neurological and psychiatric complications of chronic hypothermia following surgery for craniopharyngioma
}

\author{
A.P. Griffiths, M. Henderson, N.D. Penn and H. Tindall
}

Departments of Nuclear Medicine and Clinical Psychology, The General Infirmary, Great George Street, Leeds LS1 3EX, UK.

\begin{abstract}
Summary: A patient is described who became poikilothermic following surgery for removal of a craniopharyngioma. Episodes of disturbed behaviour, neurological abnormalities, pancytopenia and deranged liver function could be correlated with episodes of more profound hypothermia on a background of a chronically lowered core temperature. The association of pancytopenia and neuropsychiatric disturbances with hypothermia is discussed with reference to reported cases of periodic spontaneous hypothermia.
\end{abstract}

\section{Introduction}

Since the hypothalamus plays a central role in thermoregulation, abnormalities of thermoregulation should be expected in patients with tumours within or encroaching on the hypothalamus. However, in clinical practice emphasis is placed on the secondary effect of these tumours on pituitary hormone secretion and disordered thermoregulation rarely causes major difficulties in patient management. Nevertheless, it has been shown that even mild cold stress can have a detrimental effect on the performance of normal subjects on a number of tests of cognitive ability, including arithmetic, verbal memory and speed of reasoning. ${ }^{1-3}$ These studies were all performed on subjects who had only a small reduction of body temperature. There are no current reports on the performance of subjects who have a more marked reduction of body temperature.

We therefore wish to report a patient in whom persistent hypothermia has resulted in repeated admissions to hospital with unusual neurological, psychiatric and haematological abnormalities occurring on a background of chronic impairment of cognitive function, and the preventative strategies which were developed to overcome this problem.

\section{Case report}

A 40 year old man presented in June 1985 with a

Correspondence: H. Tindall M.D., M.R.C.P., Department of Medicine, Martin Wing, The General Infirmary, Great George Street, Leeds LS1 3EX, UK.

Accepted: 16 March 1988
15 year history of bifrontal headaches and decreasing visual acuity. On clinical examination, bilateral optic atrophy and bitemporal field defects were present and radiological examination showed a craniopharyngioma.

At surgery, which was performed through a right frontal bone flap, the tumour was observed immediately medial to the right olfactory nerve, and was causing displacement of both optic nerves. Highly refractile yellow fluid was drained from the cystic portion of the tumour, and calcification was noted in the solid areas which were removed. The anterior and right lateral portions of the capsule were also removed. Traction on the superior and left lateral portions of the capsule induced bradycardia and were therefore left in situ. No vessels were ligated in the course of the operation and there was no surgical interference with the overlying temporal cortex.

Shortly afterwards he was noted to be mildly mentally obtunded and forgetful. A post-operative computed tomographic (CT) scan revealed no new pathology. Pituitary function testing revealed a normal cortisol response to an insulin stress test but deficiency of thyroid stimulating hormone (TSH) and gonadotrophin secretion. Replacement therapy achieved only marginal symptomatic improvement. Pre-operatively his temperature was $36-37^{\circ} \mathrm{C}$ and in the first post-operative week was recorded at $35.5-36.5^{\circ} \mathrm{C}$.

In January 1986 he presented with a month's history of increasing apathy, lethargy and dizziness, followed by a week's history of florid hallucinations

(C) The Fellowship of Postgraduate Medicine, 1988 
and aggressive disruptive behaviour. On admission his rectal temperature was $31.4^{\circ} \mathrm{C}$, blood pressure $50 / 0 \mathrm{~mm} \mathrm{Hg}$, pulse 45 beats/minute. He had expressionless facies, titubation, monotonous speech and flapping tremor. On the following day myoclonus of the right arm and leg was present with spasticity of the arms and bilateral extensor plantars. By the fourth day of admission, his rectal temperature had risen to $34^{\circ} \mathrm{C}$ and he was lucid and orientated with no recollection of the preceding week's events. Laboratory investigations revealed haemoglobin $10.5 \mathrm{~g} / \mathrm{dl}$. white blood cells $2.1 \times 10^{9} / 1$, platelets $51 \times 10^{9} / 1$. aspartate transaminase $74 \mathrm{IU} / 1$, alkaline phosphatase 26.6 KA units (hepatic isoenzyme), creatine kinase normal, the electrolytes, glucose, urea and creatinine were all within the normal range. The chest $\mathrm{X}$ ray, blood and urine cultures were normal. Thyroid function tests and 24-hour urinary free cortisol were in the normal range. Folic acid (plasma and red-cell), vitamin $B_{12}$ and iron were normal. Viral serological screening and autoantibody screening were also normal. The cerebrospinal fluid was sterile with a protein of $1.25 \mathrm{~g} / \mathrm{l}$, and the electroencephalogram showed a diffuse slow-wave abnormality. A fourth generation CT scan with contrast was performed (Figure 1). Three millimetre contiguous cuts through the sella showed, in coronal view, an irregular calcified mass extending upwards into the hypothalamus and causing considerable distention of the third ventricle. Since the EM 1010

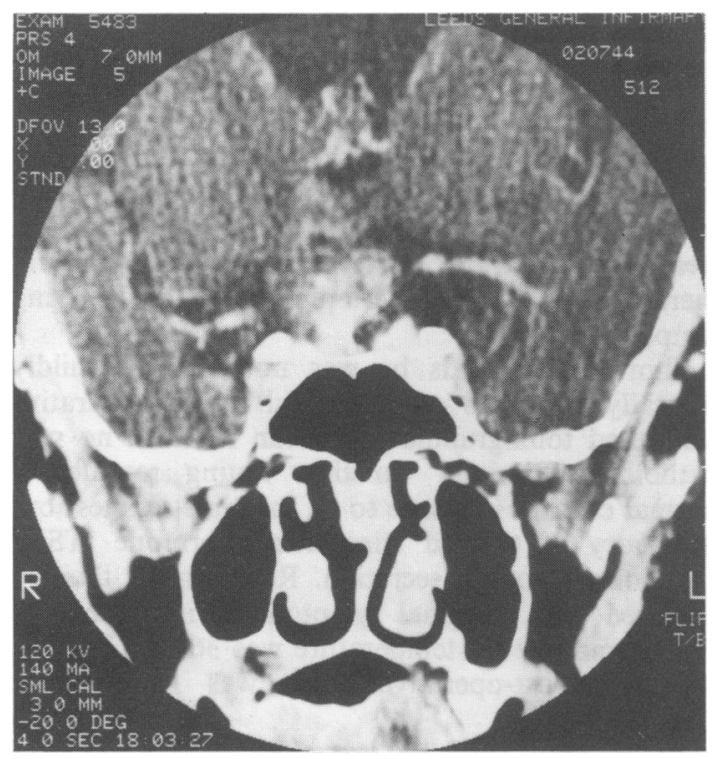

Figure 1 Coronal CT scan showing an irregular calcified tumour extending upwards into the hypothalamus and distorting the third ventricle. scan performed immediately post-operatively, the suprasellar cystic component had regenerated, and a small but definite increase in tumour size had occurred in the left posterior segment. On this high resolution scan, the overall form of the tumour and distortion of the third ventricle, however, were comparable to the appearances on the earlier EMl scan. Bone marrow aspiration showed a hypoplastic marrow and liver biopsy revealed liver cell degeneration of unknown aetiology. He was discharged home but readmitted on two subsequent occasions with similar symptoms. On each occasion rectal temperature was below $32^{\circ} \mathrm{C}$.

In July 1986 his wife found him on two occasions to be very confused after falling asleep in the garden in strong sunshine. He recovered after 24 hours resting indoors. His temperature was not recorded but his skin felt hot to touch.

\section{Results of tests of thermoregulation}

\section{Cold challenge}

This was performed in a $4^{\circ} \mathrm{C}$ cold room and lasted 40 minutes. The patient and a control were both lightly clad and oral temperature, pulse and psychometric performance were recorded. The control showed a similar fall in oral temperature to the patient (Figure 2). Although both patient and control showed piloerection and felt cold, only the control shivered.

\section{Heat challenge}

The patient was seated, half-submerged, in a bath of water at $40^{\circ} \mathrm{C}$. There was a rapid rise in temperature (Figure 2) and the test had to be discontinued after 30 minutes because the patient became mentally obtunded, with an expressionless facies, drooling saliva and flapping tremor. The control subject, immersed to the neck in water at $40^{\circ} \mathrm{C}$ for 30 minutes, showed a $2^{\circ} \mathrm{C}$ rise in oral temperature and was perspiring profusely over the face. Perspiration was not seen in the patient.

\section{Results of psychological testing}

A number of tests designed to sample a range of cognitive abilities were performed during the cold challenge (oral temp. $32.5^{\circ} \mathrm{C}$ ) and after his temperature had been restored to a more normal value of $35^{\circ} \mathrm{C}$. The results (Table I) clearly show a deficit in performance on all tests when the patient was cold, including a marked deficit in the ability to learn new information as shown by the two tests of 

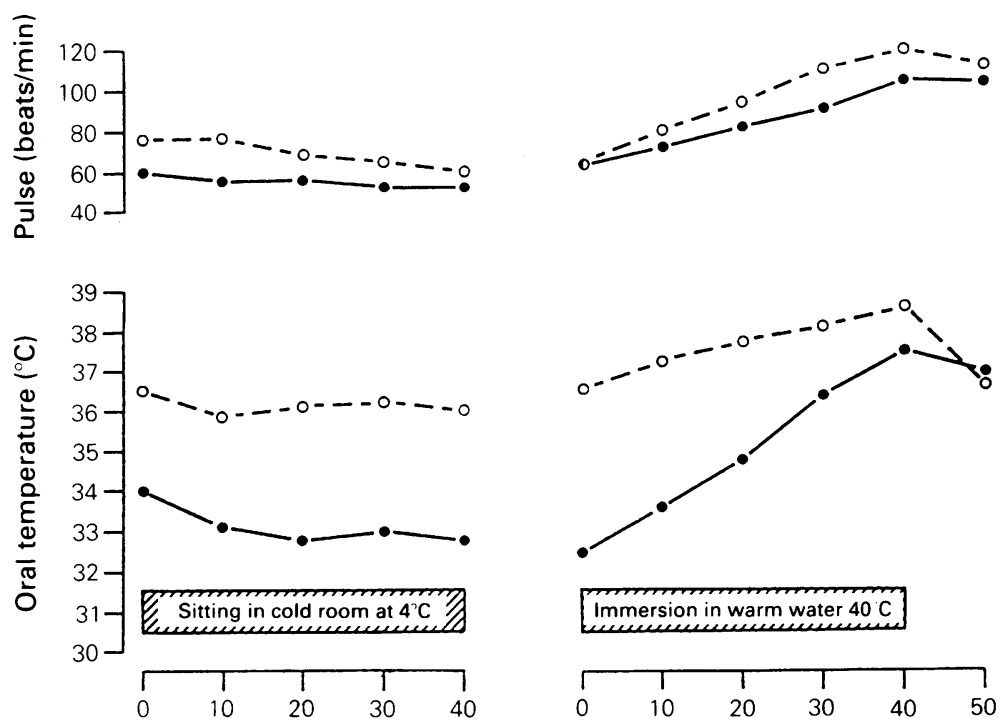

Time (minutes)

Figure 2 Response of the pulse and oral temperature of patient and control when exposed to cold and heat stress (O--- 0 , control; ---0 , patient).

Table I Results of psychological testing at core temperatures of $32.5^{\circ} \mathrm{C}$ and $35^{\circ} \mathrm{C}$

\begin{tabular}{ccc}
\hline & \multicolumn{2}{c}{ Temperature ${ }^{\circ} \mathrm{C}$} \\
\cline { 2 - 3 } Test & $\begin{array}{c}\text { Cold } \\
\left(32.5^{\circ} \mathrm{C}\right)\end{array}$ & $\begin{array}{c}\text { Normal } \\
\left(35^{\circ} \mathrm{C}\right)\end{array}$ \\
\hline $\begin{array}{c}\text { Mental control } \\
\text { (time in seconds) }\end{array}$ & 32.3 & 16.6 \\
$\begin{array}{c}\text { Paired associate } \\
\text { learning (total memories) }\end{array}$ & 7 & 15.5 \\
$\begin{array}{c}\text { Logical memory } \\
\text { (average memories) }\end{array}$ & 7 & 11 \\
$\begin{array}{c}\text { Single digit addition } \\
\text { (time in seconds) }\end{array}$ & 83 & 49 \\
$\quad$ (errors) & 0 & 1 \\
$\begin{array}{c}\text { Double digit addition } \\
\text { (time in seconds) }\end{array}$ & 141 & 51 \\
(errors) & 2 & 0 \\
\hline
\end{tabular}

memory (logical memory and paired associate learning).

To overcome these problems, levels of home heating have been increased. Both the patient and his family have been trained to recognize early signs of thermal stress and the patient has been taught to recognize potentially dangerous situations and to react appropriately.

\section{Discussion}

This patient demonstrates many interesting features; firstly, poikilothermia has only rarely been des- cribed in man; ${ }^{4}$ secondly, reports on performance of patients with hypothermia as low as $32.5^{\circ} \mathrm{C}$ have not previously been described, and thirdly, it is stated that the liver is only rarely involved in hypothermia (hepatocellular degeneration has been reported in accidental hypothermia); the elevated AST usually being derived from muscle. ${ }^{5}$

In a review of 60 patients who died of hypothalamic tumours, ${ }^{6} 18$ had some defect of thermoregulation recorded before death: 7 had pyrexia, 7 had 'defective regulation', presumably a tendency to hypothermia, 3 showed pulse/temperature dissociation and one was poikilothermic. Chronic persistent hypothermia, in which the core temperature is persistently reduced, has been reported in elderly subjects, patients with hypothalamic disease, tetraplegia, extensive dermatological disease and recently as a late sequel to head injury. ${ }^{7}$ Patients gradually become obtunded with eventual development of confusion, hallucinations, slurred speech, ataxia, rigidity, depressed reflexes, bradycardia and pancytopenia ${ }^{89}$ Although chronically hypothermic, the above patient's hospital admissions occurred during episodes of more profound hypothermia. These were similar in their presentation, particularly the neuropsychiatric disturbances, to reported cases of type II periodic spontaneous hypothermia, ${ }^{10}$ rather than chronic persistent hypothermia. In type II periodic spontaneous hypothermia, sudden inexplicable falls in temperature occur, persisting for several days or weeks, and are accompanied by bizarre psychiatric behaviour and a variety of abnormal neurological signs such as flapping tre- 
mor and spastic upper limbs. Pancytopenia and slow-wave abnormalities on the electroencephalogram are also seen. ${ }^{10.11}$ The pattern of disturbed neurological function suggests that these episodes are due to changes in core temperature (from mild, $35-32^{\circ} \mathrm{C}$, to moderate, $32-28^{\circ} \mathrm{C}$, hypothermia), and not to co-existing structural brain damage. The rapid appearance in our patient of certain of these features during immersion in a warm bath would support this view. It has been suggested that the hallucinations, induced by the cold, are due to disturbances in cerebral 5-hydroxy-tryptamine. ${ }^{11}$

From the practical point of view, recognition of the above associations is essential for developing

\section{References}

1. Baddeley, A.D., Cuccaro, W.J., Egstrom, G.H., Weltman, G. \& Willia, M.A. Cognitive efficiency of divers in cold water. Human Factors 1975, 17: 446-454.

2. Davies, F.M., Baddeley, A.D. \& Hancock, T.R. Diver performance: the effect of cold. Undersea Biomed Res 1975, 2: 195-213.

3. Coleshaw, S.R.K., Van Someren, R.N.M., Wolff, A.H., Davies, H.M. \& Keatings, W.R. Impaired memory registration and speed of reasoning caused by low body temperature. J Appl Physiol 1983, 55: 27-31.

4. Maclean, D. \& Emslie-Smith, D. Intermittent and chronic hypothermia. In: Accidental Hypothermia. Blackwell, Oxford, 1977, pp. 312-332.

5. Maclean, D. \& Emslie-Smith, D. Pathology. In: Accidental Hypothermia. Blackwell, Oxford, 1977, pp. 395-407.

6. Bauer, H.G. Endocrine and other clinical manifestations of hypothalamic disease. $J$ Clin Endocrinol 1954, 14: 13-31. preventive strategies, ensuring an equable thermal environment, and for reducing the number of investigations to which such patients may be subjected when they present with a complex pattern of psychiatric, neurological, haematological and hepatic abnormalities. The impairment of cognitive function as body temperature falls is an additional complicating factor which needs to be remembered when considering the long term management of such patients.

\section{Acknowledgements}

We are most grateful to Dr Lamb, Consultant Neuroradiologist, for his assistance in preparing this case report.

7. Ratcliffe, P.J., Bell, J.I., Collins, K.J., Frackowiak, R.S. \& Rudge, P. Late onset post-traumatic hypothalamic hypothermia. $J$ Neurol Neurosurg Psych 1983, 46: 72-74.

8. Maclean, D. \& Emslie-Smith, D. Hypothermia in the elderly. In: Accidental Hypothermia. Blackwell, Oxford, 1977, pp. 286-311.

9. O'Brien, H., Amess, J.A.L. \& Mollin, D.L. Recurrent thrombocytopenia, erythroid hypoplasia and sideroblastic anaemia associated with hypothermia. $\mathrm{Br} J$ Haematol 1982, 51: 451-456.

10. Thomas, D.J. Episodic hypothermia. Lancet 1973, ii: 449.

11. Gray, H.H., Smith, L.D.R. \& Moore, R.H. Idiopathic periodic hypothermia and bizarre behaviour in the presence of occult syringomyelia. Postgrad Med J 1986, 62: 289-290. 